\title{
IDENTIFICATION OF QUALITY ENHANCEMENT METHODS FOR SWEET ORANGE (Citrus sinencis) AT 50\% MATURITY STAGE
}

\author{
E.K.E.C. Nayana ${ }^{1 *}$ and M.A.L.N. Mallawaarachchi ${ }^{1 * *}$ \\ ${ }^{I}$ Regional Agriculture Research and Development Centre, Bandarawela \\ Email:*ekecnayana@gmail.com \\ **lankika21@gmail.com
}

\begin{abstract}
Fruits at 50\% maturity stage were selected and six different treatments were applied to find the best storage conditions where, ambient temperature packed in transparent polythene (T1), stored in black polythene (T2), without packing (T3), refrigerator packed in transparent polythene (T4), refrigerator packed in black polythene (T5) and refrigerator without packing (T6).Physiological characters (weight, firmness, juice content and rotten \%) and TSS, pH and Acidity of the initial and stored fruits were examined on every $7^{\text {th }}$ day for a period of 35 days. Sensory evaluation was conducted using 10 panelists to find out consumer preferences. During storage period minimum weight losses (from 85.1g to 73.1g), highest TSS (11.2), gradually decreasing of firmness, increase of $\mathrm{pH}$ ( from $2.6 \pm 0.1$ ) and reduction of acidity (from $1.6 \pm 0.1$ to $1.2 \pm 0.06$ ) were observed in fruits stored in refrigerator with packed of black polythene with glossy appearance yellow colour and $0 \%$ of rotten fruits. Sensory evaluation results of black colour polythene covered fruit stored in refrigerator had significantly higher ( $\mathrm{Pr}>\mathrm{F} 0.05)$ values such as $98 \%$ peel colour appearance, taste (88) and juice content (88). Therefore, stored in refrigerator packed in black polythene were the best quality fruits.
\end{abstract}

Keywords: quality enhancement; Sweet orange;maturity stage; storage conditions

\section{Introduction}

Sweet orange (Citrus sinensisL.) is, highly valued fruit crop in Sri Lanka which belongs to family Rutaceae, subfamily Aurantioideae. At present sweet orange production widely distributed in dry and intermediate zone of Sri Lanka, mainly in the Anuradhapura, Kurunegala and Badulla districts. The area under this fruit crop is increasing rapidly as a result of dynamic crop production scheme launched by Government of Sri Lanka. The sweet orange fruits primarily provide vitamin $\mathrm{C}$ and consisted with the other nutrients such as calcium, potassium, thiamin, niacin and magnesium. Sweet orange fruits were consumed fresh and used in traditional medicine as well. Therefore, it is increasingly becoming popular among people. Sweet orange variety Sisila was recently released variety from the Department of Agriculture, which was recommended to the wet and intermediate zones of Sri Lanka. This variety has good flavor, juice content and especially attractive yellowish orange peel colour at fully mature stage. However, there are considerable post harvest losses of this sweet orange fruits since it has shortest shelf life of 5-7 days (Sakhale and Kapse, 2012). Therefore, it is important to determine different storage methods to extend the shelf life of sweet orange variety Sisila with higher consumer acceptability for overall quality of orange.

The peel colour and flavor of sweet orange fruits are varying considerably with variety, climatic conditions in cultivated area, and storage conditions. Therefore, peel colour and flavor are important parameters to catch the quality perceived by consumers and to create reasonable price limits for farmers. The measure of peel colour development, total soluble solids (TSS) content, $\mathrm{pH}$, acidity, rotten percentage and firmness of fruits are 
important to access keeping quality and fruit quality in storage studies. It is necessary to improve storage conditions to keep sufficient shelf life to utilize the entire production in local as well as export market. Improper storage results in rapid loss of sugars, ascorbic acids (Faasema et al, 2011). Efforts have been made in this investigation to extend shelf life of sweet orange variety Sisila with reusable packing materials and storage conditions.

\section{Materials and Methods}

The experiment was conducted in year 2013, Horticulture laboratory at Regional Agriculture Research and Development Centre, Bandaraewla. Sisila oranges at physiologically 50\% mature stage were harvested from commercial orchard in Badulla district, packed in corrugated fiber boxes, transported to the laboratory, selected for uniformity in size, weight, peel colour and absence of defects. Selected area belongs to up country intermediate agro ecological zone. Badulla district situated in $1200 \mathrm{~m}$ height from sea level, there average temperature range is from $15^{\circ} \mathrm{C}$ to $27^{\circ} \mathrm{Cand}$ annual rain fall is around $1100-1400 \mathrm{~mm}$. Red yellow podsolic soil type is most commonly found in that area.Transparent and black colored low density polyethylene (LDPE) bags were used as packaging materials with the same gauge of 200. Separately weighed fruits were packed in transparent and black LDPE bags (200 gauge), as each bag consisting six fruits. Packed (treatments) and unpacked samples (control) were then stored at ambient $\left(24 \pm 1^{\circ} \mathrm{C}\right)$ and refrigeration $\left(8^{\circ} \mathrm{C}\right)$ temperature. Six treatments were arranged as fruits were stored in ambient temperature, packed in transparent polythene (T1), packed in black polythene (T2), without packing (T3 - Control) and fruits were stored in refrigeration condition, packed in transparent polythene (T4), packed in black polythene (T5), without packing (T6 Control). Fruit quality parameters were considered from each treatment at weekly interval such as weight, juice content, pH, TSS (expressed as Brix), Firmness, titratable acidity (TA), rotting percentage and consumer preference. Laboratory equipments; electrical balance, penetrometer, $\mathrm{pH}$ meter and hand held refractometer was used to measure fruit weight, fruit firmness, $\mathrm{pH}$ and TSS respectively.

The experiment arranged according to the Two Factor Factorial Completely Randomized Design with four replicates. Data were subjected to ANOVA to obtain treatment means using SAS 9.1.3 statistical software. The statistical differences among treatment means were tested by DUNCAN procedure $(\mathrm{P}=0.05)$ test. Sensory evaluation was done by using trained 10 number of panelist's evaluation of citrus fruits. The parameters of taste, colour and juiciness were measure. Ten numbers of panelists were involved for the sensory evaluation.

\section{Results and Discussion}

The effect of storage environment, packaging materials and storage period on fruit weight, firmness, juice content and rotten percentage were mentioned in Table 1 . The results revealed that, during the storage period, highest weight loss was recorded in fruits which were stored ambient temperature without packing. The fruits packed in black polythene, stored in refrigerator were shown the lowest weight loss.

The weight loss of six treatments was significantly increased with storage period. The main causes for weight loss were respiration and transpiration at higher temperature and high humidity level at ambient temperature. Therefore, it was observed that the fruits in ambient temperature without packing progressively increase weight loss than fruits stored in refrigerator without packing within short storage period. The difference in water vapor transmission rate in packing materials was affected to change time to reach heavy weight losses. Furthermore Gonzalez et al., (1990) mentioned lower rate of weight loss of fruits in the package could be due to slow rate of ripening and prevention of excessive moisture loss.

The storage environment and packing materials were significantly ( $\mathrm{Pr}>\mathrm{F} 0.05$ ) affect the firmness of fruits. All fruits stored under different treatments had gradually increasing possibility of firmness after 21 days storage except fruit storage in ambient temperature without packing. The firmness of T3 was decline from $1^{\text {st }}$ day of storage up to $7^{\text {th }}$ day. After on day 7 started again to increase firmness. But, fruits were stored in refrigerator 
condition packed in black polythene treatment revealed the gradually reduction of fruit firmness during the storage period.

According to the Faasema et al., (2011), reason to decrease of fruit firmness could be due to the degradation of protopectin by pectinatase. The firmness increase could be due to the hardening of the skin or development of leathery structure as a result of high water loss and the development of shriveling. The texture modifications through degradation of polysaccharides such as pectins, cellulose and hemicellulose were that could be the reason to reduce fruit firmness of T5 (Irtwange, 2006). 
E.K.E.C. Nayana and M.A.L.N. Mallawaarachchi / Identification of Quality Enhancement....

Table1: Fruit physiological characters changes in sweet orange variety "Sisila" with different storage conditions and packing materials during storage period

\begin{tabular}{|c|c|c|c|c|c|c|c|c|}
\hline \multirow[t]{2}{*}{ Store conditions } & \multirow{2}{*}{$\begin{array}{l}\text { Packing } \\
\text { materials }\end{array}$} & \multirow[t]{2}{*}{ Parameters } & \multicolumn{6}{|c|}{ Storage periods (Days) } \\
\hline & & & 1 & 7 & 14 & 21 & 28 & 35 \\
\hline \multirow{12}{*}{$\begin{array}{l}\text { Ambient } \\
\text { temperature } \\
\left(24^{\circ} \mathrm{C}\right)\end{array}$} & \multirow{4}{*}{$\begin{array}{l}\text { Transparent } \\
\text { Polythene } \\
\text { (T1) }\end{array}$} & Weight (g) & $87.1 \pm 0.3$ & $85.6 \pm 0.4$ & $81.7 \pm 1.6$ & $78.5 \pm 0.3$ & $75.6 \pm 0.3$ & $72.1 \pm 1.7$ \\
\hline & & Firmness (lb) & $15.7 \pm 0.5$ & $14.9 \pm 1.6$ & $11.1 \pm 1.6$ & $8.9 \pm 6.1$ & $9.6 \pm 1.4$ & $15 \pm 16.7$ \\
\hline & & Juice content (ml) & $36.2 \pm 7.3$ & $34.8 \pm 9.3$ & $30.2 \pm 5.5$ & $29 \pm 19.5$ & $24 \pm 10.8$ & $23.8 \pm 8.1$ \\
\hline & & Rotten $(\%)$ & 0 & 0 & 0 & 0 & 0 & 0 \\
\hline & \multirow{4}{*}{$\begin{array}{l}\text { Black } \\
\text { polythene (T2) }\end{array}$} & Weight $(\mathrm{g})$ & $85.6 \pm 1.6$ & $83.6 \pm 0.3$ & $82.7 \pm 1.3$ & $77 \pm 0.1$ & $72.5 \pm 0.7$ & $69.7 \pm 0.03$ \\
\hline & & Firmness (lb) & $18.1 \pm 0.9$ & $16.4 \pm 4.1$ & $15.1 \pm 6$ & $12.8 \pm 2.2$ & $14.4 \pm 3$ & $14.5 \pm 0.7$ \\
\hline & & Juice content (ml) & $32.4 \pm 1.9$ & $31 \pm 2.8$ & $28.2 \pm 4.4$ & $27 \pm 4$ & $25.2 \pm 5$ & $25 \pm 18.8$ \\
\hline & & Rotten $(\%)$ & 0 & 0 & 0 & 0 & 0 & 0 \\
\hline & \multirow{4}{*}{$\begin{array}{l}\text { Control } \\
\text { (T3) }\end{array}$} & Weight $(\mathrm{g})$ & $86.7 \pm 1.9$ & $78.2 \pm 2.3$ & $69 \pm 2.7$ & $65.4 \pm 3.1$ & $62.8 \pm 0.8$ & $57.6 \pm 1.9$ \\
\hline & & Firmness (lb) & $11.5 \pm 1.7$ & $9.7 \pm 1.4$ & $16.5 \pm 2.3$ & $22.4 \pm 2.6$ & $24 \pm 7.4$ & 0 \\
\hline & & Juice content (ml) & $37.5 \pm 5.4$ & $36.2 \pm 9.6$ & $29.5 \pm 4.1$ & $28.4 \pm 9$ & $27.4 \pm 5.8$ & 0 \\
\hline & & Rotten (\%) & 0 & 0 & 0 & 0 & 0 & 50 \\
\hline \multirow{12}{*}{$\begin{array}{l}\text { Refrigerator } \\
\left(8^{\circ} \mathrm{C}\right)\end{array}$} & \multirow{4}{*}{$\begin{array}{l}\text { Transparent } \\
\text { Polythene } \\
\text { (T4) }\end{array}$} & Weight (g) & $85.2 \pm 0.5$ & $83.4 \pm 2.3$ & $81.5 \pm 1.7$ & $78.9 \pm 1.3$ & $77.6 \pm 0.9$ & $74.5 \pm 0.6$ \\
\hline & & Firmness (lb) & $18.3 \pm 2.6$ & $14.8 \pm 4.4$ & $12 \pm 3$ & $8.4 \pm 5.7$ & $10.4 \pm 1.5$ & $10.2 \pm 1.2$ \\
\hline & & Juice content (ml) & $35.2 \pm 4.1$ & $29.6 \pm 4.9$ & $28.3 \pm 2.8$ & $26.6 \pm 18.8$ & $25.2 \pm 5.1$ & $22.5 \pm 6$ \\
\hline & & Rotten $(\%)$ & 0 & 0 & 0 & 0 & 0 & 0 \\
\hline & \multirow{4}{*}{$\begin{array}{l}\text { Black } \\
\text { polythene (T5) }\end{array}$} & Weight $(\mathrm{g})$ & $85.1 \pm 2.6$ & $84.7 \pm 0.5$ & $82 \pm 1.1$ & $80.4 \pm 0.7$ & $77.8 \pm 0.4$ & $73.1 \pm 1.2$ \\
\hline & & Firmness (lb) & $19.1 \pm 3.2$ & $18 \pm 7.6$ & $14.6 \pm 1$ & $12.4 \pm 0.9$ & $11 \pm 3.6$ & $10.1 \pm 3$ \\
\hline & & Juice content (ml) & $31.5 \pm 1.9$ & $28.8 \pm 5.6$ & $27.8 \pm 6.8$ & $27.3 \pm 11.2$ & $26.2 \pm 4.6$ & $25 \pm 6.9$ \\
\hline & & Rotten $(\%)$ & 0 & 0 & 0 & 0 & 0 & 0 \\
\hline & \multirow{4}{*}{$\begin{array}{l}\text { Control } \\
\text { (T6) }\end{array}$} & Weight $(\mathrm{g})$ & $86.3 \pm 1.7$ & $83.1 \pm 0.6$ & $80.1 \pm 1.3$ & $77.5 \pm 2.1$ & $72.7 \pm 2.3$ & $69.4 \pm 0.9$ \\
\hline & & Firmness (lb) & $16.4 \pm 3.1$ & $15.1 \pm 1.7$ & $13.8 \pm 1.7$ & $13.1 \pm 1.6$ & $14.6 \pm 2.5$ & $16.8 \pm 3.4$ \\
\hline & & Juice content (ml) & $32 \pm 4.2$ & $27.7 \pm 7.9$ & $27.7 \pm 3.2$ & $23.5 \pm 5$ & $24.1 \pm 5.2$ & $22.4 \pm 7$ \\
\hline & & Rotten $(\%)$ & 0 & 0 & 0 & 0 & 0 & 0 \\
\hline
\end{tabular}


Proceedings of the $4^{\text {th }}$ International Conference on Agriculture and Forestry, Vol. 3, 2017, pp. 1-9

Table 2: Fruit biochemical characters changes in sweet orange variety "Sisila" with different storage conditions and packing materials during storage period

\begin{tabular}{|c|c|c|c|c|c|c|c|c|}
\hline \multirow[t]{2}{*}{ Store conditions } & \multirow[t]{2}{*}{ Packing materials } & \multirow[t]{2}{*}{ Parameters } & \multicolumn{6}{|c|}{ Storage periods(Days) } \\
\hline & & & 1 & 7 & 14 & 21 & 28 & 35 \\
\hline \multirow{9}{*}{$\begin{array}{l}\text { Ambient } \\
\text { temperature } \\
\left(24^{\circ} \mathrm{C}\right)\end{array}$} & \multirow{3}{*}{$\begin{array}{l}\text { Transparent } \\
\text { polythene } \\
\text { (T1) }\end{array}$} & TSS & $9.4 \pm 0.3$ & $9.7 \pm 0.8$ & $9.7 \pm 0.5$ & $9.8 \pm 4.6$ & $10.2 \pm 0.6$ & $10.4 \pm 0.7$ \\
\hline & & $\mathrm{Ph}$ & $2.7 \pm 0.2$ & $2.9 \pm 0.1$ & $2.9 \pm 0.2$ & $3.1 \pm 1.4$ & $3.2 \pm 0.1$ & $3 \pm 0.1$ \\
\hline & & Acidity & $1.5 \pm 0.5$ & $1.5 \pm 0.3$ & $1.5 \pm 0.7$ & $1.5 \pm 0.6$ & $1.4 \pm 0.4$ & $1.4 \pm 04$ \\
\hline & \multirow{3}{*}{$\begin{array}{l}\text { Black polythene } \\
\text { (T2) }\end{array}$} & TSS & $9.7 \pm 0.7$ & $10 \pm 1$ & $10.1 \pm 0.8$ & $10.4 \pm 1.4$ & $10.2 \pm 0.8$ & $10.2 \pm 0.5$ \\
\hline & & $\mathrm{pH}$ & $2.9 \pm 0.7$ & $2.9 \pm 0.1$ & $3.1 \pm 0.4$ & $3.2 \pm 0.1$ & $3.2 \pm 0.1$ & $3.3 \pm 0.1$ \\
\hline & & Acidity & $1.6 \pm 0.7$ & $1.5 \pm 0.4$ & $1.4 \pm 0.2$ & $1.4 \pm 0.6$ & $1.3 \pm 0.4$ & $1.3 \pm 0.1$ \\
\hline & \multirow{3}{*}{$\begin{array}{l}\text { Control } \\
\text { (T3) }\end{array}$} & TSS & $9.9 \pm 1.2$ & $9.9 \pm 0.6$ & $10.1 \pm 1.2$ & $9.7 \pm 0.5$ & $9.2 \pm 0.2$ & 0 \\
\hline & & $\mathrm{pH}$ & $2.7 \pm 0.3$ & $2.8 \pm 0.1$ & $3 \pm 0.1$ & $3.2 \pm 0.1$ & $2.9 \pm 0.2$ & 0 \\
\hline & & Acidity & $1.5 \pm 0.4$ & $1.4 \pm 0.1$ & $1.2 \pm 0.1$ & $1.2 \pm 0.05$ & $1.5 \pm 0.3$ & 0 \\
\hline \multirow{9}{*}{ Refrigerator $\left(8^{\circ} \mathrm{C}\right)$} & \multirow{3}{*}{$\begin{array}{l}\text { Transparent } \\
\text { Polythene } \\
\text { (T4) }\end{array}$} & TSS & $9.7 \pm 0.5$ & $9.8 \pm 0.6$ & $9.9 \pm 0.8$ & $10.4 \pm 5.2$ & $10.6 \pm 0.9$ & $10.8 \pm 0.6$ \\
\hline & & $\mathrm{pH}$ & $2.7 \pm 0.02$ & $2.9 \pm 0.1$ & $3 \pm 0.1$ & $3.1 \pm 1.4$ & $3.3 \pm 0.1$ & $3.4 \pm 0.1$ \\
\hline & & Acidity & $1.6 \pm 0.1$ & $1.5 \pm 0.3$ & $1.5 \pm 0.2$ & $1.4 \pm 0.1$ & $1.4 \pm 0.3$ & $1.3 \pm 0.1$ \\
\hline & \multirow{3}{*}{$\begin{array}{l}\text { Black polythene } \\
\text { (T5) }\end{array}$} & TSS & $9.8 \pm 0.6$ & $9.9 \pm 1.1$ & $10.2 \pm 0.9$ & $10.8 \pm 1.1$ & $10.9 \pm 0.9$ & $11.2 \pm 0.7$ \\
\hline & & $\mathrm{pH}$ & $2.6 \pm 0.1$ & $2.9 \pm 0.2$ & $3 \pm 0.03$ & $3 \pm 0.04$ & $3.2 \pm 0.1$ & $3.6 \pm 0.08$ \\
\hline & & Acidity & $1.6 \pm 0.1$ & $1.5 \pm 0.1$ & $1.5 \pm 0.5$ & $1.4 \pm 0.5$ & $1.3 \pm 0.1$ & $1.2 \pm 0.06$ \\
\hline & \multirow{3}{*}{$\begin{array}{l}\text { Control } \\
\text { (T6) }\end{array}$} & TSS & $9.7 \pm 0.2$ & $8.9 \pm 0.7$ & $9.6 \pm 0.7$ & $9.6 \pm 0.5$ & $9.7 \pm 1.4$ & $10.8 \pm 0.6$ \\
\hline & & $\mathrm{pH}$ & $2.8 \pm 0.4$ & $2.9 \pm 0.08$ & $3.1 \pm 0.1$ & $3.1 \pm 0.2$ & $3.2 \pm 0.2$ & $3.3 \pm 0.04$ \\
\hline & & Acidity & $1.6 \pm 0.2$ & $1.6 \pm 0.4$ & $1.5 \pm 0.2$ & $1.5 \pm 0.6$ & $1.5 \pm 0.1$ & $1.5 \pm 0.3$ \\
\hline
\end{tabular}


Gradual decreasing pattern of juice content had been recorded in all treatments. Sweet orange fruits stored in refrigerator and packed using black polythene were shown the low reducing pattern of juice content. The reason to reduce juice content was transpiration of water from fruits.

From the beginning of storage of every treatment up to $28^{\text {th }}$ day $\left(4^{\text {th }}\right.$ week) were not shown significant rotten percentage of fruits. Significantly higher rotten percentage had been shown in T3 (50\%). Therefore, shelf life of those fruits was end after $28^{\text {th }}$ day and not suitable for human consumption.

In Table 2 was shown the TSS, $\mathrm{pH}$ and acidity of sweet orange fruits in different treatments. Different packing materials and two different environmental conditions had been significantly affected (Pr>F 0.05) the TSS. The significantly highest TSS values were recorded in fruits stored in refrigerator packed in black polythene (T5). Throughout the whole experimental period, every treatment in refrigeration condition was shown gradually increasing of TSS. Moreover, transparent and black polythene covered fruits stored in ambient temperature were recorded gradual increasing of TSS up to $35^{\text {th }}$ day. After $14^{\text {th }}$ day of storage, TSS value of fruits stored in ambient temperature without packing (T3) was gradually declined. The fruits of T3 have attained maximum TSS of $10.1^{0}$. The decrease in TSS because, exhaustions of acids and the conversion of sugars in to other organic products as substrate for respiration (Faasma et al, 2011). The same results were recorded by Znidarcic et al, (2010) as TSS increase in both storage conditions under ambient and refrigerator conditions. Because of degradation of polysaccharide was reported as possible reason of increasing soluble solids contents in fruits with the increase of maturity.

Rohani et al, (1997) mentioned, the increase in TSS is related to ripening of fresh commodities while slower rate of respiration may reduce metabolic activities and thus result in to lower TSS values. The above statement line with Ishaq et al, (2009), TSS value was considerably increased during storage due to fully conversion of starches in to soluble sugars. At the same time decline in TSS during storage period attributed to fermentation of soluble sugars in to alcohol, $\mathrm{Co}_{2}$ and water (Majidi et al, 2011).

The fruits which stored in refrigerator packed in black polythene were recorded significantly increasing $\mathrm{pH}$ value. According to the Castro et al, 2005, pH value was increased with fruit maturity. It has been further reported that packaging films significantly affected ripening rates of fruit (Faasema et al, 2011).

Acidity value of T5 (Pr>F 0.05) was lower than the acidity of fruits of other storage conditions. The all treatments except T3 were shown the decreasing values of acidity during storage. Acidity values of T4 and T5 were not significantly different. As in literature, Faasema et al, 2011 mentioned, organic acids decline during ripening of fruits and they used as substrates for respiration or converted in to sugars. According to that reason $\mathrm{pH}$ value becomes higher. 


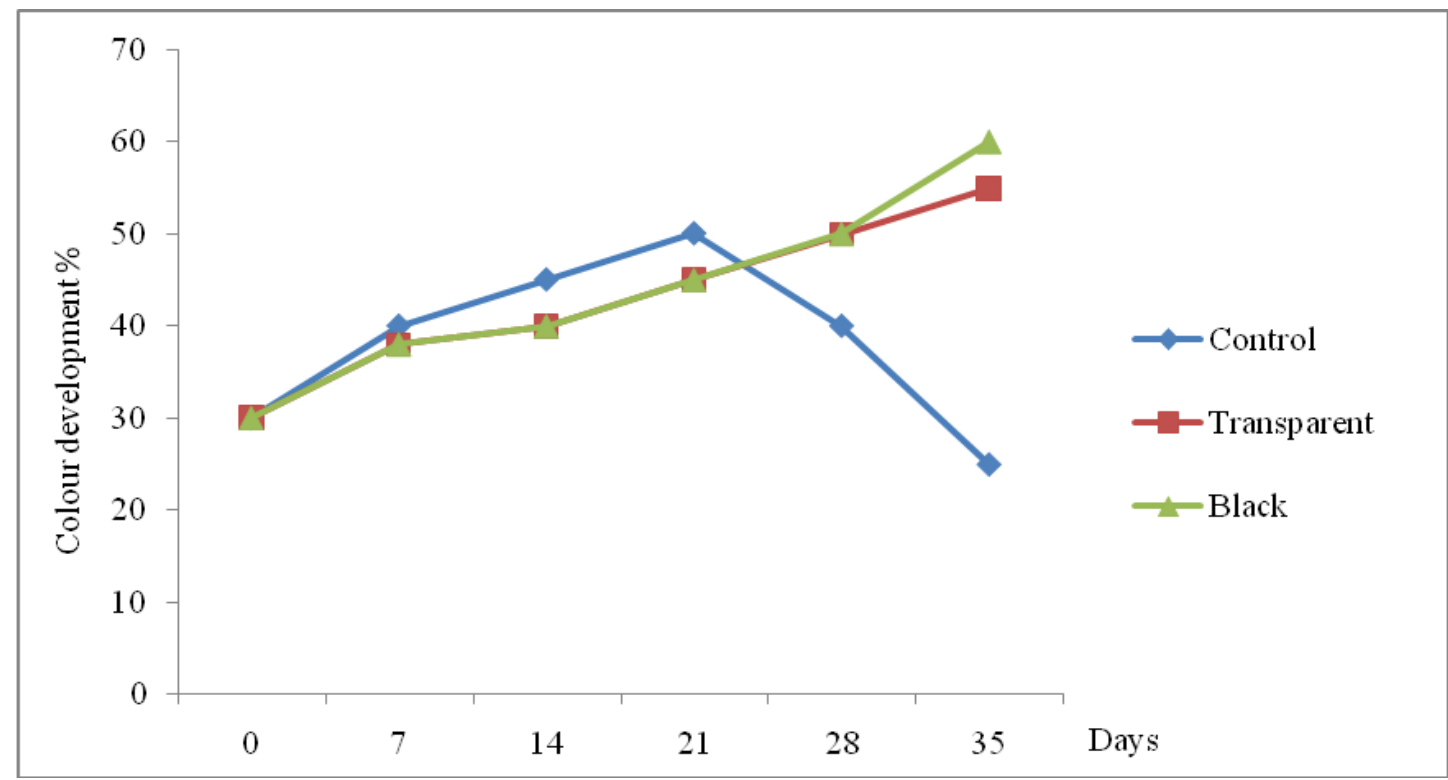

Figure1 Peel colour development percentage of sweet orange variety "Sisila" with different packing materials at ambient temperature

According to the Figure 1, peel colour development percentage was gradually increase up to $35^{\text {th }}$ day of fruit packed in transparent and black polythene. After the $28^{\text {th }}$ day, sudden colour development improvement was seen in black polythene covered samples, but not significantly different. Control sample in ambient temperature was shown colour development improvement up to $21^{\text {st }}$ day during storage period. After that, development of discolouration was appeared.

Even though, samples stored in refrigeration condition were shown gradual increasing pattern in colour development (Figure 2). The slow colour development percentage was observed only in control treatment up to day 21 and other two treatments were shown significantly ( $\mathrm{Pr}>\mathrm{F} 0.05$ ) higher colour development percentage up to day 35 . Within those two treatments, glossy appearance and smoothness were higher in samples packed in black polythene.

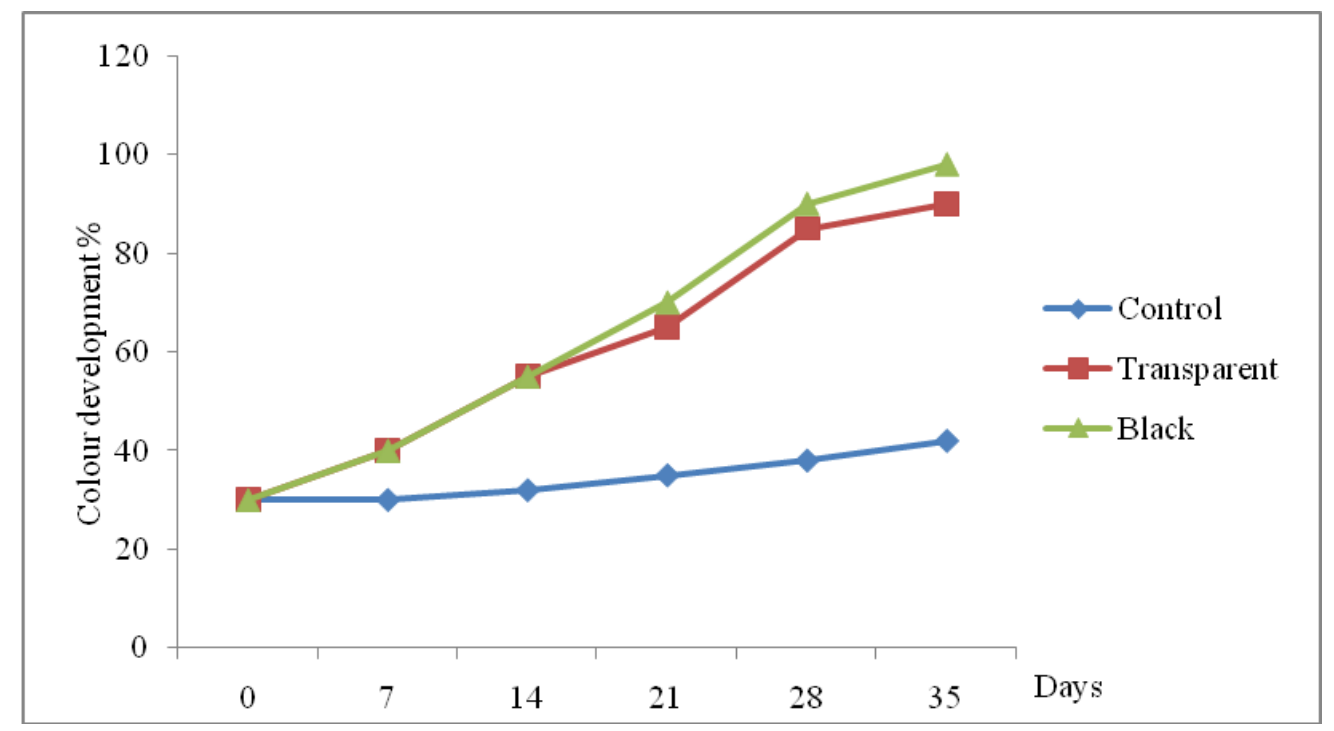

Figure2 Peel colour development percentage of sweet orange variety "Sisila" with different packing materials at refrigerator condition 


\section{Sensory evaluation}

Consumer preferences were measured by sensory evaluation of sweet orange fruits. Peel colour was measured as percentage. Significantly highest peel colour development (bright yellow with glossy appearance) was recorded in fruits stored in refrigerator packed in transparent and black polythene bags. The values were $95 \%$ and $98 \%$ respectively. Very poor colour development was observed in fruits stored in ambient temperature without packing. The reason was, the peel became shriveling by the heavy water losses through transpiration. Therefore, instead of yellow colour development, brown colour appearance was taken place.

Table 3 Sensory evaluation of sweet orange variety "Sisila" with different treatments

\begin{tabular}{llll}
\hline \multirow{2}{*}{ Treatment } & \multicolumn{2}{l}{ Parameters } & \\
\cline { 2 - 4 } & Peel colour $(\%)$ & Taste & Juiciness \\
\hline T1 & $62^{\mathrm{b}}$ & $58^{\mathrm{b}}$ & $48^{\mathrm{c}}$ \\
\hline T2 & $65^{\mathrm{b}}$ & $63^{\mathrm{b}}$ & $49^{\mathrm{c}}$ \\
\hline T3 & $25^{\mathrm{d}}$ & $12^{\mathrm{d}}$ & $13^{\mathrm{d}}$ \\
\hline T4 & $95^{\mathrm{a}}$ & $72^{\mathrm{a}}$ & $82^{\mathrm{a}}$ \\
\hline T5 & $98^{\mathrm{a}}$ & $88^{\mathrm{a}}$ & $88^{\mathrm{a}}$ \\
\hline T6 & $40^{\mathrm{c}}$ & $28^{\mathrm{c}}$ & $57^{\mathrm{b}}$ \\
\hline CV\% & 7.2 & 5.3 & 11.7 \\
\hline
\end{tabular}

Note: Means followed by the same letter in each column are not significantly different at $\mathrm{p}=0.05$

The value of "taste" was significantly highest in fruits stored in refrigerator packed in black polythene. The lowest taste was recorded in fruits stored in ambient temperature without packing. The high level of transpiration at ambient temperature directly affected the lowest quality of fruits. Juiciness also significantly highest in fruits stored in refrigerator packed in transparent and black polythene.

\section{Conclusion}

Results revealed that the shelf life of fruits of Sweet orange variety "Sisila" could be extended in refrigeration condition by packing with black polythene. Fruit physiological characteristics, biochemical properties and consumer preferences were highest in fruits in black polythene cover stored under refrigerator. Similarly, fruit quality was highest in fruits stored in refrigerator packed in black polythene up to day 35 . Very poor shelf life was observed in the fruits stored in ambient temperature without packing. Loss of glossy appearance, shriveling, symptoms due to water loss and dryness of peel directly affected to the poor consumer preference and marketability of those fruits.

\section{References}

Castro, L. R., Vigneault, C., Charles, M. T., and Cortez, L. A. B., 2005, Effect of Cooling Delay and Cold chain Breaakge on "Santa Clora"Tomato, Journal of Food Agriculture and Environment, 3, 49- 54.

Faasema, J., Abu, J. O., and Alakali, J. S., 2011, Effect of packaging and storage condition on the quality of sweet orange (Citrus cinensis). Journal of Agricultural Technology, 7(3), 797-804.

Gonzale, G., Yahita, E. M., and Higuera, I., 1990, Modified atmosphere packaging (MAP) of Mango and Avacado fruit. ActaHort, 1-12.

Irtwang, S. V., 2006, Application of modified atmosphere packaging and related technology in post harvest handling of fresh fruits and vegetables. AgricEng Inter, 4, 1- 12. 
Ishaq, S., Rathore, H. A., Masud, T., and Ali, S., 2009, Influence of post harvest Calcium Chloride application, ethylene absorbent and modified atmosphere on quality characteristics and shelf life of apricot (PrunusarmeniacaL.) fruit during storage. Pak. J. Nutr., 8(6), 861- 865.

Majidi, H., Minaeir, S., Almasi, M., and Mostofi, Y., 2011, Total soluble solids, titratable acidity and ripening index of Tomato in various storage conditions. Aust. J. Basic App.Sci., 5 (12), $1723-1726$.

Rohani, M. Y., Zaipun, M. Z., and Norhayati, M., 1997, Effect of modified atmosphere on the storage life and quality of Eksotika papaya.Journal of Trop. Agric. Food Sci., 25, 103-113.

Sakhale, B. K., and Kapse, B. M., 2012, Studies on shelf life extension of sweet oranges (Citrus sinensis L.). Ïnteernational Food Research Journal, 19(2), 779-781.

Znidarcic, D., Ban, D., Oplanic, M., Karic, 1., and Pozrl, T., 2010, Influence of post-harvest temperature on physiochemical quality of Tomatoes (Lycopersiconesculentum Mill). Journal of Food, Agriculture and Environment, 8, 21- 25. 